\title{
MUSIC THERAPY FOR SUPPORTING \\ COMMUNICATION DEVELOPMENT FOR \\ YOUNG CHILDREN WITH COMPLEX \\ NEEDS IN A SPECIALIST CONDUCTIVE \\ EDUCATION SERVICE
}

An exegesis presented in partial fulfilment for the requirement for the degree of

Master of Music Therapy

New Zealand School of Music

Victoria University of Wellington

Wellington, New Zealand

Qiaoling Liang (Nika)

2020 


\section{Abstract}

This research aimed to explore the ways in which I, as a music therapy student, could benefit speech and language development with children with complex needs in an early childhood service. Communication is one of the most important parts of our lives. It helps us to connect and build a relationship with others, families, friends and so on. Speech-language development is a core part in music therapy of Communication development for young children which aim to help children to express their inner feelings, emotions; to improve children's understanding communication and interpret information from other people (Perry, 2003; Knight \& Rabon 2017). This is theoretical exploratory research which contains various data from music therapy literature, music therapy audiovisual recordings in public domains, and reflective notes from general experience on placement. This research used a thematic analysis method. The data was interpreted in an open inductive way, discovering ideas and combinations of codes without assumptions, and finding new ideas from the sources. The data analysis method followed the guidelines of Braun \& Clarke in 2006 which included six steps in the process: 1) familiarizing with data, 2) generating initial codes, 3) searching for themes, 4) reviewing themes, 5) defining and naming themes and 6) providing a report. This research found there were three main themes in response to the question how do music therapists support speech and language for young children. The most important fundamental process was "Building trust and familiarity" between therapist and child; the secondary theme or process was "Moving up together" which involved musical collaboration and enjoyment. Throughout these processes therapists used "flexible musical skills". This exploratory study also helped me as a student music therapist to better understand how to facilitate and support speech and language development in my placement in a specialist conductive education facility. 


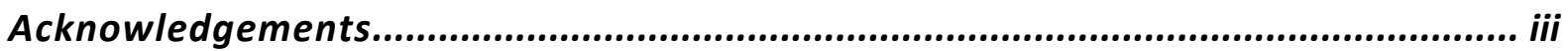

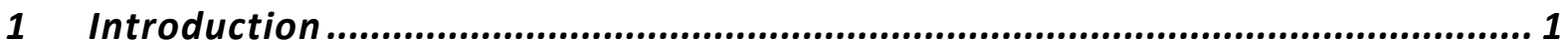

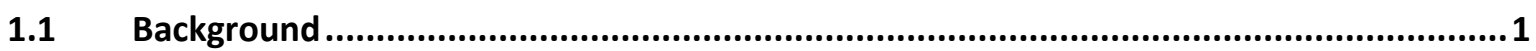

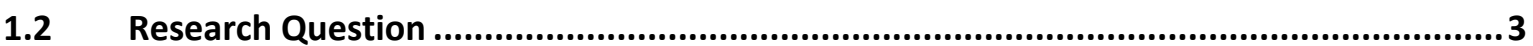

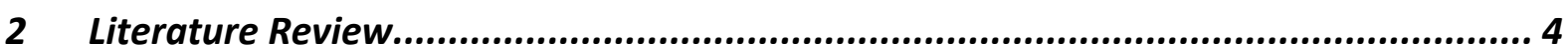

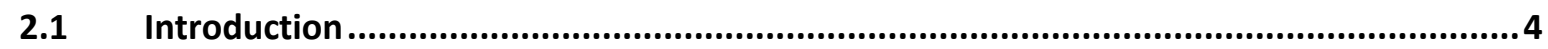

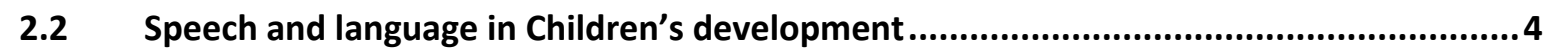

2.3 Music therapy supports speech and language development.......................................5

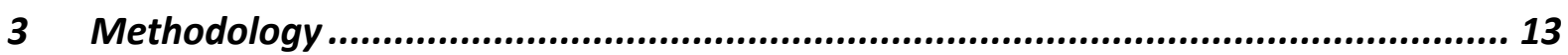

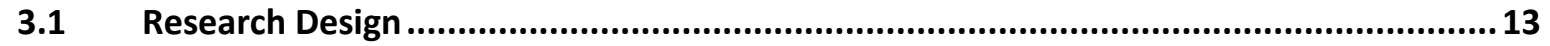

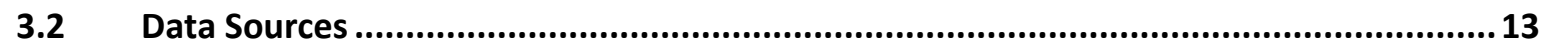

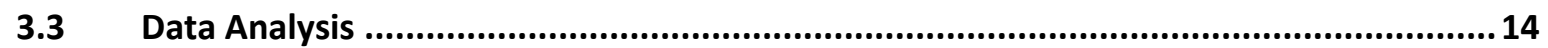

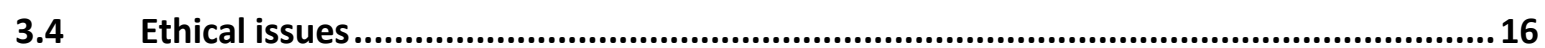

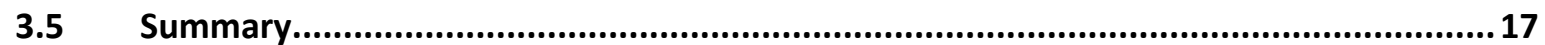

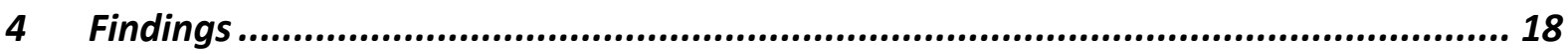

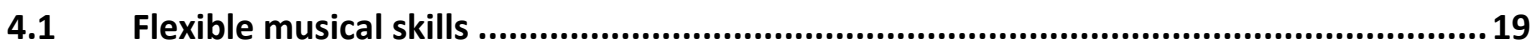

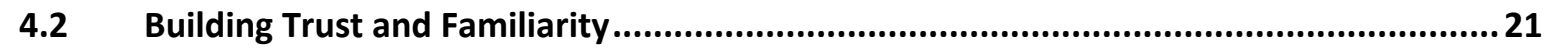

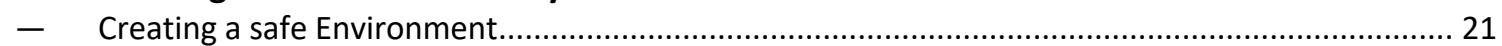

4.2.2 Following the child's lead (Clinical improvisation method) ……............................................... 25

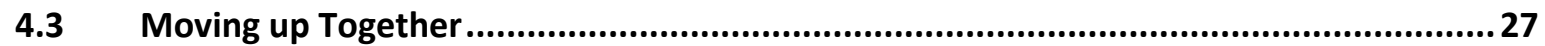

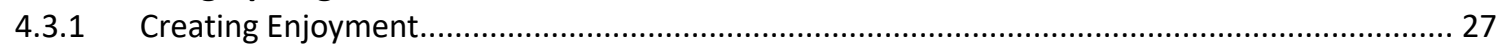

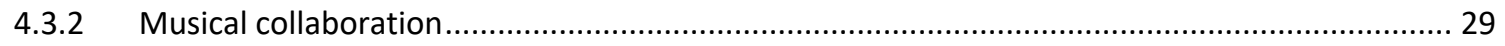

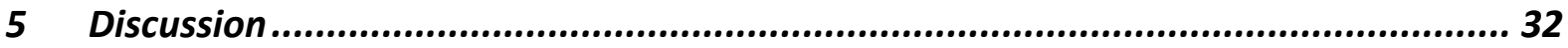

5.1 What I found essential from this research relating to my practice experience ...............32

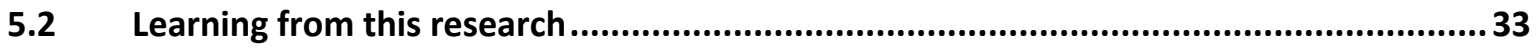

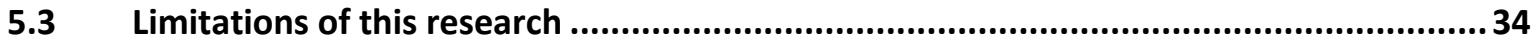

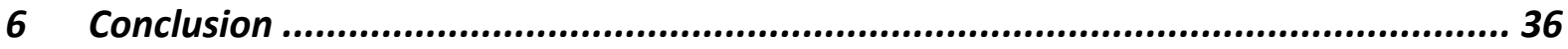

APPENDIX 1: AN EXAMPLE OF CODING FROM THE VIDEO DISCRIPTIONS ....................... 37

APPENDIX 2: AN EXAMPLE OF CODING FROM THE LITERATURE (PERRY (2003))............. 37

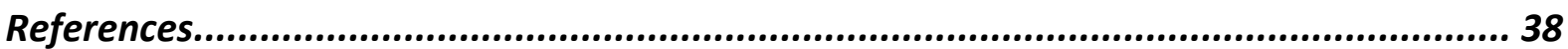




\section{Acknowledgements}

This research is conducted at a difficult period. I would like to acknowledge and express my huge appreciation to the following people:

To my research supervisor, Associate Professor Sarah Hoskyns, for giving me help and advice during the period, I wandered in foreign countries under the travel restrictions in March; always being patient with guiding me with the literature, the analysis, the pressure, the writing, the software; and comforting me when I felt frustrated and upset during the whole year.

To Associate Professor Daphne Rickson and my clinical supervisor Kimberley Wade, for supporting me throughout my placement and in research.

To my classmate Xiu, for your endless support during the hardest time; understanding me and keep encouraging me when I was suffering the language difficulties in reading and writing; helping me with the travelling in Wellington.

To my family, my mother, father and my brother in particular, for always supporting and respecting my decisions in life and learning; being with me any time through the difficulties.

To Nordoff-Robbins Music Therapy, for sharing a number of great video resources in the public domain, which provides me with a lot of thinking and learning in this research.

To Ryan Judd, a board- certificated music therapist, for sharing various meaningful video resources in YouTube channel, which helped me to rich data from different music therapy side. 


\section{Introduction}

\subsection{Background}

I am fortunate to have a chance to work at a Conductive Education (CE) centre in New Zealand as my second-year clinical placement. CE is an early intervention programme for preschool children who are living with complex needs. These include such conditions as physical disabilities (including cerebral palsy), developmental delay, and Autism Spectrum Disorders, premature babies, sensory processing difficulties and feeding difficulties. Children attend group sessions depending on their age and needs. The families can choose home-based services or to attend group sessions in the centre.

The CE centre provides different services for children to develop various abilities with their peers in an educational environment. The centre consists of two big indoor rooms and one outdoor play area for children to explore. One indoor room is for physical supporting; children are encouraged to do walking, climbing, jumping and other physical excises in this room. The other one is an exploration and eating room with plenty of toys, instruments as well as books for children to play and explore for free. And children are also having their morning tea and lunch in this room. All learning and training programmes are designed based on group or team form, which provides children opportunities to develop social communication skills, team collaborations as well as respecting each other during the group environment. The outdoor playing area has various equipment which includes balls, swings, sand pool, slide, bicycles.

The centre opens four days a week: Monday, Tuesday, Thursday and Friday. Both Monday and Thursday are provided physical development programme by the conductor. Children attend this programme with their parents, and one early intervention teacher's accompanying. Children learn and practice to control every part of their body, such as mouth, hands, arms, legs and feet.

The goals of CE include:

- Personality development

- Independent living

- Coordination development 
- Speech and language development

- Sensory integration

- Motor functioning

- Motor control

- Learning

- Physical adaptation

- Psychological acceptance

- Emotional exploration

- Social interaction

I usually work in the centre each Monday, Tuesday and Friday. My works include group and individual music activities. On Monday, Tuesday and Friday morning, we have "Connecting and relating" group activities for children, in which I usually collaborate with other staffs. I play the guitar and sing, while other staffs help me to model the movement and support children. We have musical instrument activities (such as play the drum and shakers); body movements activities (such as walking, rocking, standing and sitting follow the music); Child-like games (such as Peek-a-boo game, lycra shaking, bobbles popping). Most children are non-verbal or have speech and language delay. The goal of this group is facilitating the social and communication skills for children by using music to engage children to play and collaborate with peers, and relating as a whole.

When working with this population, improving communication abilities such as communication intent, receptive language, and expressive language was one of my main goals. I think I have a special sensitivity to this area, as an international student who was speaking English as a second language in New Zealand. I was suffering a language barrier and experiencing the stresses caused by communication difficulties at that time. When I could use language and find a way to express my inner feelings, or I could not understand the meanings what others said, some challenging emotions such as "awkwardness, anxiousness, helplessness, stress as well as lack of confidence" were generated. Hence, I realized the importance of communication amongst life, and I chose to focus on music therapy with speech and language development area as my research topic in my second-year study.

From the beginning of the year, the COVID-19 Virus spreads throughout the world. Many countries, including China and New Zealand, chose to lock down the country to protecting 
people's lives. Thus, the start of my practicum was delayed, and I, therefore focus my research on what can be learned from literature, interaction with team members, and online resources.

\subsection{Research Question}

How do music therapy practitioners and students support speech and language development through the use of voice, song and improvisation for young children with complex needs?

The purpose of this research is to explore how music therapy supports speech and language development for young children with complex needs. This research focuses on finding out through literature, online video and documented experiences of the research what other music therapists do to help children with speech and language difficulties and what approaches and strategies are addressed. 


\section{Literature Review}

\subsection{Introduction}

This literature review focuses on how music therapy support speech and language development with children with complex needs in early childhood. The resources of literature were mainly collected from music therapy and children communication development-related research articles, peer-reviewed music therapy journals and book chapters. When I was looking for materials, I used the keywords as "Music therapy", "Improvisation", "Speech and language" as well as "Early childhood" in Te Waharoa of Victoria University of Wellington. This literature describes speech and language in children's development and how music therapy can support speech and language development. According to my research question and direction, I mainly focus on "How" and "What strategies and techniques" in the literature.

\subsection{Speech and language in Children's development}

There is a critical period for children's brain development early in life, from birth to around eight years old (Tierney \& Nelson, 2009). Joshi \& Shukla (2019) observe that children's learning is holistic, and the main areas of brain development are movement and physical skills, emotion, cognition, language and communication, and socialization

As learning to communicate with the world is one of the key areas, supporting children to express emotions and communicate to others has become an important task in music therapy (Tuomi, 2017; Kern, 2006; Lim, 2010; Perry, 2003). The Ministry of Education in 2007 outlined five key competencies in The New Zealand Curriculum document which included 1) thinking; 2) relating to others; using language, symbols, and texts; 3) managing self; and 4) participating as well as 5) contributing. Bruce (2012) also prioritises language development as one of the important areas in the growth of young children, especially with children with developmental delays. 
Communication mainly consist of two parts: speech and language. The speech represents the way that is expressing using voice, including the accuracy of pronunciation, fluency in speaking, etc. Language is, the specific way we describe our inner thoughts, feelings through learning, understanding the form and function of a people understanding system, which including sign language, spoken words, writing words (American Psychological Association, 2013).

The speech and language development in music therapy was stressed with children with communication disorders (Gross, Linden Ostermann, 2010; Guerrero Turry, 2012). Knight \& Rabon in 2017 said music therapy is an effective way to enhance speech and language development in early childhood populations. Speech-language development is a core part in music therapy of Communication development for young children which aim to help children to express their inner feelings, emotions; to improve children's understanding communication and interpret information from other people (Perry, 2003; Knight \& Rabon 2017).

Understanding the developmental stages and milestones are essential for music therapist working with children in early childhood (Perry, 2003; Lorenzato, 2005; Wheeler, Shultis, \& Polen, 2005). Early childhood can be divided into three age ranges: infancy range from birth to about age two; toddlerhood ranges from age two to age three, and preschool age from age three to age five. Children's development is a continuous and ongoing process with building from one stage to another. It includes several domains such as cognitive, social and emotional, language, fine and gross motors. In children's development process, different development speed may occur in different areas. For example, a child has typical physical development may have speech and language delay.

\subsection{Music therapy supports speech and language development}

The development of musicality from both nature and nurture affect the progress of brain. Music can stimulate infants' hearing and responses. Sustaining music stimulation may cause changes in the brain. Music therapy provides good supports in areas of auditory processing, speech and language processing (LaGasse, 2017; Miendlrzewska \& Trost, 2014; Perry, 2003; Knight \& Rabon, 2017). 
Music is an essential part of young children's life. Rhythm and sounds are the two main musical elements that relate to a child. Babies feel the rhythm of heartbeats and hear mother's singing while in utero. Children grow and learn through music experiences. Music is a bridge for children connecting and building trust with others (Pavlicevic, 2000; Feldberg, 2000).

Music therapy has been shown to be that helpful and useful to enhance children's speech and language communication development (Aldridge 1996; Davis, Gfeller, \& Thaut, 2008; Nicholls, 2002; Tyler, 2002).

A growing number of studies indicate that music therapy can facilitate many various areas in early childhood, such as enhancing emotional regulation; and developing skills of social and communication as well as encourage general development (LaGasse, 2017, Tuomi, 2017; Perry, 2003). The common goals for music therapy in early childhood are the control of gross and fine motor control; communication; age-appropriate social skills; attention and focus; following instructions; body awareness \& self-regulation; sensory integration; ageappropriate concepts (Tuomi, 2017).

Understanding children's developmental milestones help the music therapist understand their difficulties, determine strategies, techniques, musical activities that can best suit for children's needs (Bunning, 2003; Perry, 2003; Newham, 1998; Wilkinson, 2008). A number of music therapists in their studies acknowledge that choosing the most appropriate methods and approaches to individualize each child's specific needs, levels is a critical part when working with preschool children. (Aldridge, 1996; Beathard \& Krout, 2008; Bunning, 2004; DeThorne et al., 2009; Grosz et al., 2010; Hoskyns, 2009; Malloch \& Trevarthen, 2009; Oldfield, 2006; Wheeler, 2015; Wright \& Kersner, 2001).

For those children who are non-verbal, providing a tool to convey their emotions, to communicate with others is essential in children's development. Hartley, Turry, \& Raghavan (2010) described that music has a similar language function; it can express human emotions, especially when the emotions are strong or complex. For example, people often can understand the strong emotional feelings through the musician's performance without any words communications. Music uses many elements to convey emotions that similar to speech \& language's prosody, such as pitch, tempo, accent, volume, pause, breath in music 
which could also be found in speech. The dictionary defines nonverbal communication as all meaningful communication other than oral communication, such as the use of gestures and facial expressions, body indications, etc. ("nonverbal communication," n.d.).

Sawyer (1999) thought that $90 \%$ of conversation in our daily life is improvisation. People choose speaking words, tones and tempo based on the current mood and thinking. Similar to that, clinical improvisation of music therapy also has those features. Participants play their own music, and the music therapist adjusts according to the atmosphere, dynamic, moods at the moment.

Aldridge (2008) agrees that improvisation can be considered as a musical language that provides opportunities for participants to learn communication skills through the music they made. Participants could be heard and understand within the clinical improvisation process. Pavlicevic (2000) describes clinical improvisation as 'human communication in sound'. The expression in the face, eyes, body, gestures, speaking rhythm within the clinical improvisation are all inseparably linked to the communication nature. Pavlicevic (2000) believes that the purpose of music therapy is not just to make beautiful music, but to focus on how to learn to build intimate relationships between music therapist and participants in the production process( Pavlicevic, 2000).

There are some typical clinical improvisation methods and techniques that are used, which are mirroring, grounding, matching, empathic improvisation, reflecting, dialoguing (Bruscia, 1987; Wigram, 2004; Carroll \& Lefevre, 2015). According to literature, the most common instruments that used in clinical improvisation are the piano, percussion as well as the guitar (Bruscia, 1997; Wigram, 2004; Darnley- Smith \& Patey, 2003).

Emotional regulation plays an essential role in children's development. It affects children's capacity to facing and dealing with psychological challenges with growing up. And it also reduces the risk of emotional or mental problems. Ozdemir (2009) mentioned that if children do not have enough emotional regulation abilities to deal with the negative stress or strong emotions, it might increase the risks of self-harm or harm to others. Working in a playful musical environment can facilitate children to develop emotional regulation skills naturally (Sena Moore \& Hanson- Abromeit, 2015). 
Several articles discuss the role of play and playfulness within the music therapy culture working with children. They considered this is the core concept of musical interaction, we creating a playful musical atmosphere, including playful musical activities and songs are helpful and critical when working to facilitate the development of speech and language with young children in early childhood (Bunt \& Stige, 2014; Perry, 2003). Kenny, in her research, stressed the importance of playing in music therapy, and it is inseparably connecting and linking to young children's development period (Kenny, 2006). Bunt\& Hoskyns agree with that children are more engaged in a playful and imaginative environment, and it encourages children to develop positive impressions by the sounds and music they make through exploring instruments and the use of voice freely ( Bunt \& Hoskyns, 2002 ).

Some music therapists in their studies confirmed that young children need to develop their sense of experiences, reality, self-awareness, and to improve the sense of self-exploration, creativity and imaginativeness in their development. They suggested that providing enough space for children to play and explore freely is helpful to reach those goals (McMahon, 2009; Stern, 1977; Winnicott, 1971). Beathard \&Krout (2008) and Hoskyns (2009) said that children with speech and expressive language difficulties are more engaged with doing free and playful vocal exploration (Beathard \& Krout, 2008; Hoskyns, 2009). It is helpful for young children to improve narration ability through providing children chances to express their emotions in music therapy, such as doing free vocal creation and exploration like vowel sounds "ah", “oo", “ee” etc. (Bunt, 2014; Oldfield, 2006). Beathard and Krout (2008) further considered that encouraging children to initiate any vocal sounds such as mimicking animal, vehicle sounds while participant to musical activities, instrument or toy exploring (Beathard \& Krout, 2008).

McMahon considered that children are inspired to associate reality with ideas by experiencing the free exploration and creation of the play and the release of imagination in the process of repeated experiments. (McMahon, 2009)

Music Therapy New Zealand stresses the principles of Te Tiriti o Waitangi (Treaty of Waitangi) as one of the core principles of music therapy practice in the Code of Ethics (Music Therapy New Zealand, 2012). This principle emphasis the partnership between young children, their families and the therapist. Alderson (2008) observed that music therapists should respect children's rights, thinking and behaviours when working with young children. 
She also considered that young children should learn interpersonal skills and develop the partnership in early childhood development (Alderson, 2008). Some speech and languagerelated literature indicate creating a safe, supportive, and playful environment helps children feel relaxed and develop speech and language naturally (McCarthey et al., 2008).

Music therapy can provide good opportunities for children to experience being involved in musical conversation through listening to the music made by the music therapist, and being listened to during the musical interaction (Aldridge, 1996; Hoskyns, 2009). These experiences facilitate many speeches and language skills such as building and developing social and communication skills, self-awareness, connecting and relating to others (Aldridge, 1996; Grosz et al., 2010).

Lowry (2016), Hoskyns (2009) and Oldfield (2000, 2006) emphasize that using a clientcentred music therapy approach which provides a child with equality, safety and respect, as well as a playful musical environment, can be considered as an essential part of working with young children. Young children are easier to engage and pay more attention to others when someone talks about his/her interesting things, plays his/her favourite songs (Lowry, 2016). Following a child's lead or interests can facilitate the engagement, social and communication intent as well as the sense of relatedness (Carpente, 2017). A number of studies (Aldridge, 1996; Grosz et al., 2010; Hoskyns, 2009; Michel \& Jones, 1991) show that each young children in developmental delay might have different needs in various areas. Considering individualized strategies, techniques and approaches to meet each child's specific needs are important when working with young children with special needs. Music therapy can provide structure and context in sessions which enables them to occur naturally. (Aldridge, 1996; Grosz et al., 2010; Hoskyns, 2009; Michel \& Jones, 1991).

Some literature suggests that choosing appropriate and tailored songs and videos based on each child's individual needs, and interest are essential (Aldridge, 1996; Grosz et al., 2010; Hoskyns, 2009; Michel \& Jones, 1991). Encouraging children to recreate children's familiar songs such as Row Row Row your Boat, If you are happy, Five little Monkeys, can improve children's engagement and anticipation, and motivate contribution content in the music, and evoke the sense of achievement and ownership (Beathard \& Krout, 2008; DeThorne et al., 2009; Michel \& Jones, 1991). Many music therapists found that involving singing familiar nursery songs, Peek-a-boo and finger games, animal and vehicle sound imitation within the music therapy activities can help children to reduce anxiety. And it helps build the concepts 
of communication including sharing, relatedness, collaboration skills (Beathard \& Krout, 2008; Hoskyns, 2009; Oldfield, 2000, 2006).

Many pieces of literature emphasize that music therapists should have abilities to be flexible at the moment. And using multiple strategies and techniques to match children's arising needs such as matching, modelling, musical dialoguing, turn-taking, mirroring, fill in the gap as well as creating musical pause (Leung,2008; Oldfield, 2006). Oldfield in 2006 emphasized singing, playing, talking, and music-making was important when working with children.

Wigram(2004) and Rickson(2019) in their studies noted that encouraging young children to engage turn-taking is one core part when working with young children. Music therapy can naturally promote turn-taking within many musical activities such as structured or free improvisations, singing or instrument playing. Turn-taking within musical conversation brings an experience for children to wait for a turn, and tolerate the waiting in a patient, playful and relaxed way (Wigram, 2004; Rickson, 2019). Turn-taking within musical improvisation is evoking a response from both young children and music therapists. And it also helps to improve joint attention, listening to others that are able to affect children's communication development( Bunt, 1994; Wigram et al., 2002).

Bruscia stressed the importance of promoting musical dialogue working with young children (Bruscia, 1987). Wigram in his study provides valuable examples of musical cues for therapists to enable dialoguing, such as rhythm, harmonic, rhythmic, melodic, dynamic and timbre cues, to make it obvious that the music is coming to the end of a statement or asking a question (Wigram, 2004). Brathwaite and Sigafoos found that creating musical cues can create more communication opportunities and encourage more communication responses (Braithwaite, \& Sigafoos, 1998). Leung and Silverman suggest that pairing rhythm patterns with speech patterns in musical activities are very helpful to facilitate young children's speech and working memories (Leung, 2008; Silverman, 2007). Nordoff and Robbins represented an opinion that supporting children to follow the rhythmic pattern within musical communication is essential between music and language (Nordoff and Robbins, 1983).

Oldfield described her experience working with clients using strategies such as slow the tempo down, allowing time to the participants and providing variety in the sessions (Oldfield, 2006). Some authors mentioned other relevant musical techniques in their studies, such as reflecting, accompanying, matching (Bruscia, 1998; Bunt \& Hoskyns, 2002; Wigram, 2004). 
Some music therapists considered clinical improvisation should include verbal interaction. They suggest that playing music in the therapeutic process is important. However, generating verbal interaction, speaking to participants are also critical in facilitating speech and language development (Nicholls, 2002; Nolan, 2005; Pavlicevic, 2000). This idea was also stressed in Simpson's study in 2000. He was concerned that verbal interaction plays a necessary and critical role in creative music therapy. He described that the 'verbal relationship must play a part, simply because it exists: it would be unnatural not to speak, it must be allowed to integrate naturally into the therapy’ (p. 90) (Simpson, 2000). Some literature suggests that vocal and verbal interactions supported by music can assist children's communication skills, and cognitive abilities more generally in development ( Loewy,1995, 2004; Pavlicevic, 1997). Loewy further recommended that using vocal holding technique, grounding and mirroring in music therapy are helpful to support and evoke participant's vocal response (Lowey, 2004). This vocalized dialoguing strategy be found important to facilitate the relationship between mother and infant, music therapist and the participant (Pavlicevic, 2000).

Furthermore, collaborating with other relevant specialists or professionals, sharing information, matching therapeutic goals as well as adopting strategies and techniques to support each other's area are considered extremely useful (McCarthy et al., 2008). For example, when working in a place that has several specialists such as speech and language therapist, physical therapist, conductor, early education teacher, having a regular meeting with them to discuss the development of the child, exchange some valuable information, as well as knowledge, is important.

\section{Summary}

A number of pieces of literature discuss that creating a safe and playful music therapy environment is essential. Allowing children to play, create, explore, have fun and relax in the environment is useful to facilitate young children's development. Music therapists need to understand children's development milestones, understand children's difficulties. And then to determine strategies, techniques, musical activities that can best suit for children's need (Beathard \& Krout, 2008; Hoskyns, 2009; Malloch \& Trevarthen, 2009; Wilkinson, 2008).

Respecting a child as an equal musical partner involves following their lead, talking about things, singing songs as well as playing games that go along with their interests to enhance 
their engagement, participant, and building up the connection within a social context (Lowry, 2016; Grosz et al., 2010; Hoskyns, 2009).

Music therapists should provide a flexible structure and context with multiple techniques working with young children with special needs. A number of studies show that clinical improvisation is useful. This method required the music therapist to be flexible to manage children's needs and respond to the child in the moment. There are plenty of techniques that have been suggested in the literature, such as matching, turn-taking, mirroring, slow down, repeating, and mirroring (Oldfield, 2006; Bruscia, 1998; Bunt \& Hoskyns, 2002; Wigram, 2004).

Some authors hold an opinion that verbal or vocal interaction should be included within music therapy activities. It helps children to connect the musical communication and social communication in our daily life together (Nicholls, 2002; Nolan, 2005; Pavlicevic, 2000; Simpson, 2000; Loewy,1995, 2004; Pavlicevic, 1997).

Other than that, considering collaboration or having regular meeting with other child-relevant specialists are also essential and helpful (McCarthy et al., 2008). 


\section{Methodology}

\subsection{Research Design}

This research was designed to discover the processes and the meaning within music therapy practice and to develop student theory building. It is based on the principles outlined by Bruscia in his research chapter which I understand as: how do I understand what supporting communication development in music therapy is; and what is done from my (music therapy student) perceptions and how should we apply these understandings to other works from theorists and practitioners (Bruscia, 2005).

The goal of this exploratory research is to discover ideas and insights of music therapy with speech and language development in early childhood. It aims to find out "what is going on here", figuring out what kind of interventions, resources and practical support music therapists provide; what meaning they give to their actions; and what issues are considered for various levels of support. The results of exploratory research can provide important insights into specific situations, and give some indications about "why" and "how" practitioners do what they do. And this methodology attempts to generate a theory from the data itself (Stebbins, 2001).

Bruscia considered qualitative research as "a process wherein one human being genuinely attempts to understand something about another human being or about the conditions of being human by using approaches which take full advantage of being human" (1995b, as cited in Wheeler, 2005, p. 63).

\subsection{Data Sources}

This theoretical exploratory research involved

- Literature which focused on music therapy with speech and language in early childhood. The literature includes research articles, chapters in books, peer-reviewed electronic publications as well as peer-reviewed journals. I identified 10 sources and prioritised more recent examples where these were available. Some of the sources were "case-based" to identify more detail about approaches and techniques. Reading an amount of useful and relevant books and articles was a critical part of this research. As researcher I developed and explored the knowledge and understandings from the 
literature. It provided an opportunity to gather multiple theories and principles with an open mind and to synthesise these in the analysis process.

- Review and analysis of music therapy practice audiovisual recordings available in the public domain was a part of the data source in this research. It mainly undertook to discover information about how music therapists worked with early childhood, contexts of practice and what approaches they used. When reviewing and analysing different audiovisual recordings, it provided a chance to observe through different perspectives and viewpoints. It also gave an opportunity to think about the active principles be used by the music therapists in the recordings (based on my own level of knowledge as a student.) I chose 4 examples of short video case examples, observed them a number of times and wrote session descriptions which provided the data for coding.

- Reflection notes of communication which documented personal observations, reflections, my comments from research supervision, and critical thinking, reflectively commenting on the practice and research. It also included the reflection notes of meetings with about general practices in early childhood. When working in the Conductive Education centre as a music therapy student, collaborating with other experts such as speech and language therapist, early childhood teachers, early intervention teachers, child's parents and careers is also a part of a music therapist's valuable practice in the music therapy programme. The main contents include children's health, behaviours, cooperation model and methods, programme planning and goal setting.

\subsection{Data Analysis}

This research uses the thematic analysis method. The data was interpreted in an mainly inductive way. This involved looking at relevant details from the data, creating codes and interpreting what it means and what happened with an open mind and without any assumptions (Braun \& Clarke, 2006). I used NVIVO (QSR International) Vs12 to assist me with coding the data (Appendix 1, gives an example of video description coding; Appendix 2 
gives an example of coding of article Perry (2003)). The data analysis process followed the guidelines of Braun \& Clarke in 2006:

\section{Familiarizing and understanding with the data.}

After collecting an amount of data, I read and re-read several times to ensure that I understand and get familiar with the contents of the data. I kept reminding myself with the research questions and asked myself again and again whether the data that I chose relevant to the research question, and why? After thinking carefully, I deleted some not relevant parts from my notes. For example, I needed to remind myself that my question is focusing on what the music therapist did, and how he/she did, and why. Although the big descriptions about the child's reaction and responses were interesting, I decided to remove them from my data because it confused me and made me get lost during the data analysing process.

\section{Generating initial codes from the data.}

In this stage, I started to highlight any content that is significantly relating to my research question focus: "How do music therapy practitioners and students support speech and language development through the use of voice, song and improvisation for young children with complex needs? "I highlighted all the techniques that the music therapist did with his/ her participant based on my understanding of literature. For example, I highlighted "the music therapist sang 'twinkle twinkle little ....., like a diamond in the....' The music therapist left a gap in the phrase" from one of my video descriptions and coded it as "sing-song" and "create a gap". After reviewing my initial codes, I added a new code as " using the familiar song".

\section{Searching for themes from the initial codes.}

I was very confused at this stage initially. I struggled how to get started to analyse and sort out my codes. After discussing it with my supervisor and re-reading the article (Braun \& Clarke,2006) again and again, I broke this process into two stages: 1) Sort out codes with collecting and combining similar codes into a category. 2) Establish an idea to the group. For example, I grouped "use staccato", "use glissando", "change 
harmony sequences" into a category and name it as "professional musical techniques". After classifying all initial codes, the theme generated between the categories.

\section{Reviewing themes \\ V. Defining and naming themes.}

I combined step IV and step V together. I kept reviewing the code categories and my themes, and thinking about how those themes related to my research question. Can it explain and answer my question logically, whether they make sense. I constantly changed and renamed the title of themes, until I think it can perfectly explain all ideas in each classification.

\section{Finalize themes and start to write.}

The last step was to arrange all the themes in a narrative and logical sequence until they could be described and explained as a story and conveyed my understanding perfectly.

\subsection{Ethical issues}

This research was approved in proposal form by the Postgraduate Committee (PGC) of the New Zealand School of Music. As a developing practitioner and researcher, I have been guided by Victoria University Human Ethics Guidelines (2019), and the Code of Ethics for the Practice of Music Therapy in New Zealand (2012).

Because of COVID-19 challenges, I developed an exploratory theoretical study, with reflections on my learning, but no direct or active participation from people at my placement. At the time of beginning my research, there was no possibility of engaging with children on placement and as noted previously I began my practice four months after the start of the second year course. Thus the research was considered as low risk, with only my own participation as a student reflecting on reading and discussions with advisers. The committee acknowledged that this was a well-developed proposal for the situation, in I could take into account the constraints of the COVID-19 restrictions as well as being relevant to my learning. 
As I completed my analysis, I had had more experience in contact with children's sessions at conductive education and so my reflections became more confident and were more connected with my own facilitation and musicianship. Under more normal conditions, I would have been able to use the ethical template developed by my lecturers for action research, case study research or secondary analysis of data. My lecturers applied for approval for this template in 2019 (application \# 028127)

\subsection{Summary}

This theoretical exploratory research mainly used thematic analysis of qualitative data which are drawn from the literature review, observation notes of audiovisual recordings, reflective notes, and notes from general communication with children experts as well as my research supervisor. All data were analysed used the thematic analysis method (Braun \& Clarke, 2006) which included six steps of analysis: familiarising with data, generating initial codes, searching for themes, reviewing themes, defining and naming themes as well as producing the report. There were no active participants in this research which could be considered as low risk. 


\section{Findings}

The following mind map illustrated my coding and theme generating process. I used "Xmind" (XMind Ltd, 2006 ) software to create this mind map. It helped me to organize my thoughts, and to identify my findings in a clearer and more logical way. In this chapter, I will describe my two big themes, and then illustrate each level of the underlying subthemes and codes through providing supporting theories from literature, descriptions of videos. In each process, I will explain the techniques and strategies used by music therapists from videos and literature in detail.

After dozens of repeated analyses and classified codes based on my understanding from related literature, I divided my result into three main themes: 1) Flexible Musical Techniques 2) Building trust and familiarity, and 3) Moving up Together. The first theme "Flexible Musical Techniques includes timing, tempo adaption, and dynamic adaption. The second "Building trust and familiarity" consist of two steps: 1)Understanding and Respecting what the child's doing; and 2) Following the child's lead. The third theme "Moving up Together" contains two subthemes: 1)Creating enjoyment; and 2) Musical collaboration.

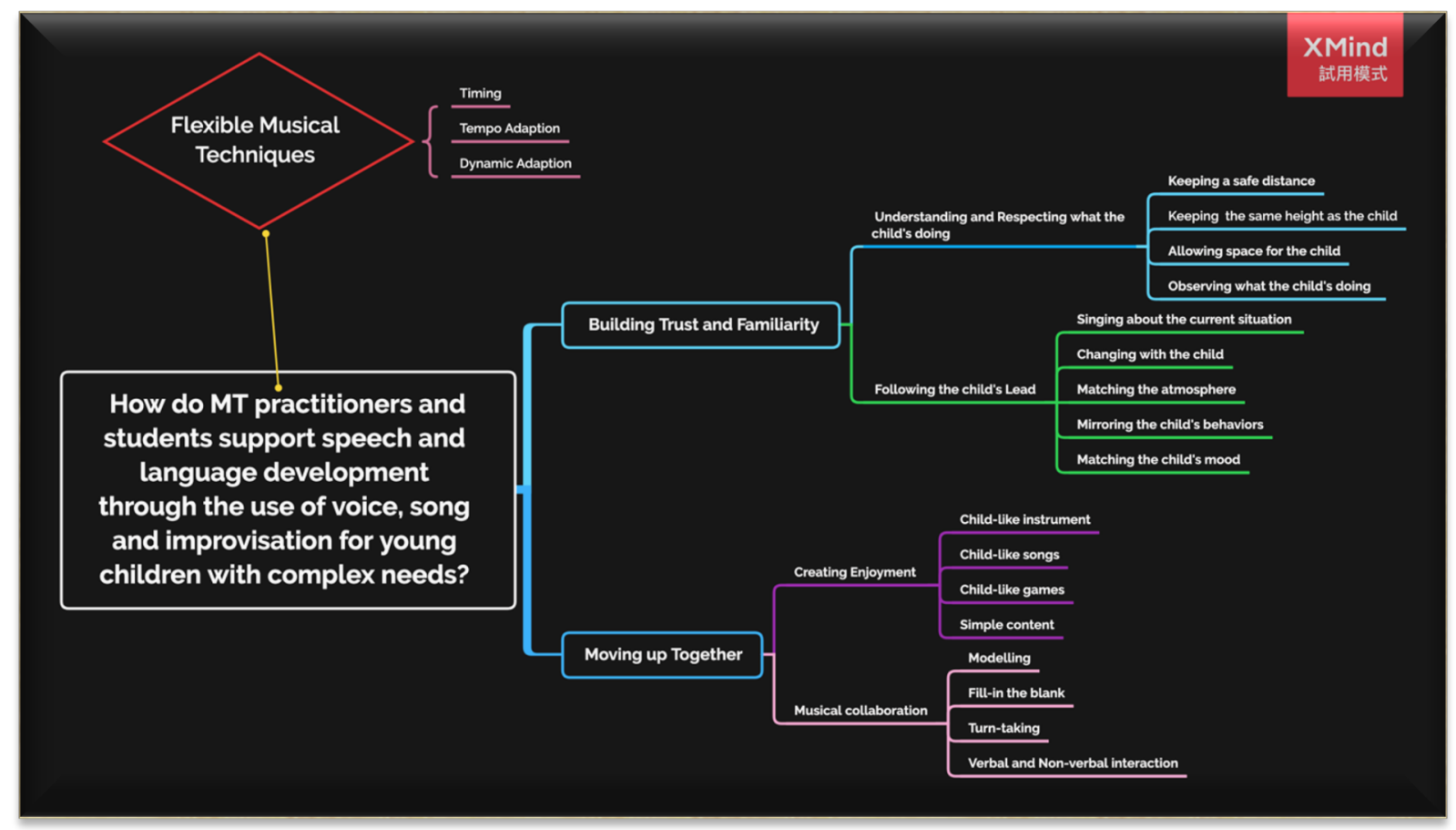




\subsection{Flexible musical skills}

Child-centred improvisation methods that include use of voice, instruments and songs seem an essential approach for a music therapist. This method requires the music therapist to be attentive and "flexible", in particular following the child's lead. However, this approach also requires a number of musical skills. For example, a professional music therapist needs to have the abilities of 1) playing music in a variety of styles and idioms, 2) to adapt flexibly across musical instruments and voice, and to adjust elements of music (e.g. pitch, timing quality) to support participants in a sensitive way.

I summarized three musical techniques that music therapists used a lot in music therapy sessions.

They are:

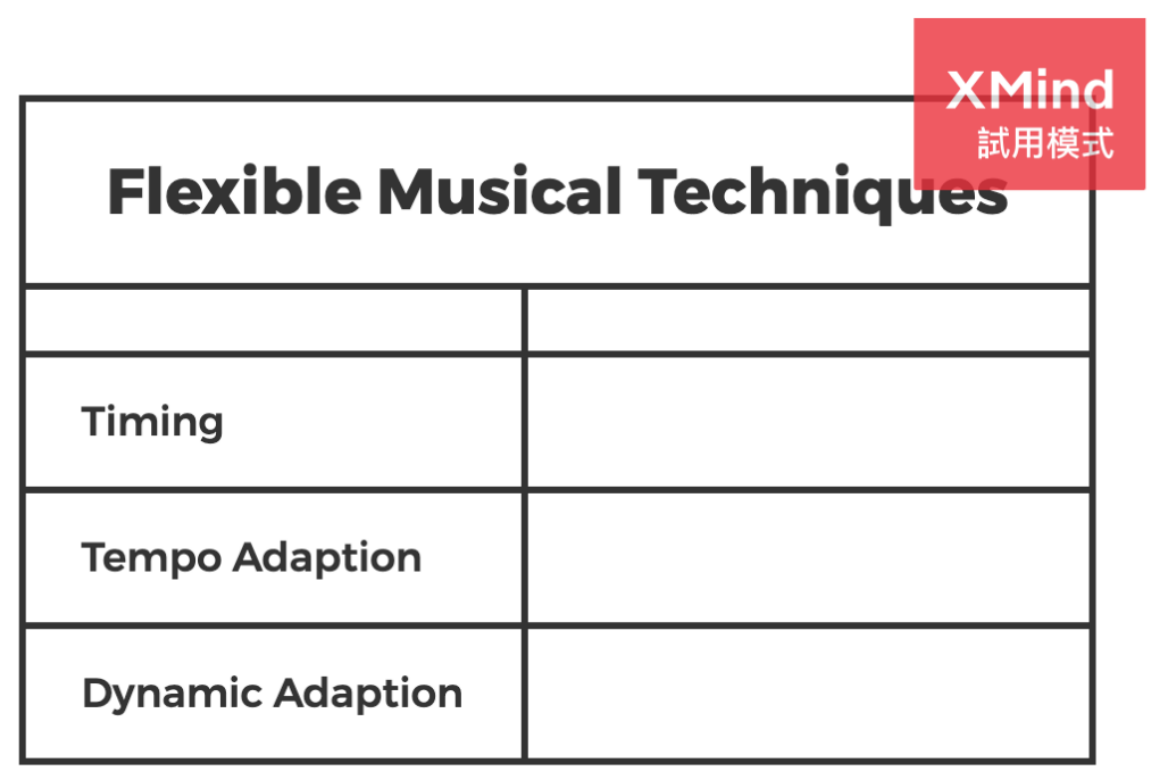

Timing

Timing carefully with the child participant's behaviour is helpful to build a connection between the music therapist and participant. And it can arouse the child's interest and catch his/her attention immediately. There is a lack of detailed descriptions about timing in literature. However, it seems essential in music therapy. According to my own understanding and observation of videos, timing is where the music therapist plays the instrument or is 
making sounds match the cues of body movements, verbal, vocal that are provided by the participant (such as arm lifting movement, nodding head) at the same time. It helps the participant be aware that somebody is there "present" with her/him. It can also catch the child's attention quickly.

For example:

When the girl waved her right arm, the music therapist scratched her right hand on the keyboard. And the music therapist played staccato and short chords when the girl waved her arm up and down quickly. The way of playing on the keyboard, including the volume, speed, timbre depending on the participant's actions (Description of video "Mary and Antonia").

\section{Tempo Adaption}

Young child participants need more time to process and understand messages than adults. Adapting the music playing or singing tempo to the child appropriate tempo is important. Slowing down the tempo and allowing time to the child participant provide auditory comfort and help them to reduce anxiety.

An example from literature:

'Tempo is almost universally understood as the "speed" or "velocity" of music, and is determined by the frequency rate of repetition of beats within a given time frame. This is typically expressed as beats per minute (bpm), and is generally in the range 40-200 bpm. Tempo variably influences a multitude of responses, from motor activity to perception of emotion in music, to arousal and motivation. Elevated tempted to require and induce increased muscle contractions, whereas slower tempi tend to be associated with muscle relaxation. Tempo also affects perception of mood in music. However, the effect may be mediated by the influence of tempo on arousal, more than a straight-line effect on mood. Whereas tempo seems to function as an amplifier of sorts, influencing in part the extent to which we experience mood states, mood seems to be influenced to a greater degree by tonal aspects of music, specifically by mode or scale.'( Thaut, 2016, p26).

\section{Dynamic Adaption}


Music therapists vary the playing volume based on the child's current feeling, dynamics and emotional state. For example, if the child shows exciting at the moment, the music therapist should play the music stronger. When the child is singing softly, the music therapist should reduce the playing volume matches the child's level. Changing the volume with the child promote the relationship between the child and the music therapist. And it also facilitates the child's engagement to the music-making. "Dynamics in music generally refer to changes in the intensity or amplitude of the sound, often spoken of in terms of "loudness" and "softness.” As many improvisation experiences are conducted utilizing percussion instruments, including piano, dynamic ranges are created by fluctuations in the use of force applied to these instruments" (Thaut, 2016, p37).

For example:

The music therapist was playing his guitar, and the boy is singing. He sang a long "Ai $\sim$ " in about $F$ note, and then changed to $E$ and $G$ with a crescendo. The music therapist played the guitar, changed the chords, and changed the strength from softer to louder matched the boys singing. The boy gave an eye-contact to the music therapist before he changed the pitch to G, and the music therapist changed the chord at the same time (Description of video "Music therapy shows how musical improvisation benefits children with special needs).

\subsection{Building Trust and Familiarity}

\section{- Creating a safe Environment}

\section{$\checkmark \quad$ Understanding and Respecting the child's doing $\checkmark$ Following the child's lead}

Some authors emphasize that using the client-centred music therapy approach which is providing a child an equal, safe, respecting as well as the playful musical environment, can be considered as an essential part working with young children (Lowry,2016; Hoskyns, 2009; Oldfield, 2000, 2006).

This theme emphasises that young children need to develop the participants and partnership with families and others (Music Therapy New Zealand, 2012). Alderson (2008) described that music therapists should respect children's rights, thinking and behaviours working with young children. She 
also considered that young children should learn international skills and develop the partnership in early childhood development (Alderson, 2008). Some speech and language-related literature indicate creating a safe, supportive, and playful environment helps children feel relax and develop speech and language naturally (McCarthey et al., 2008). Pavlicevic believes that the purpose of music therapy is not just to make beautiful music, but to focus on how to learn to build intimate relationships in the production process (Pavlicevic, 2000).

The first fundamental stage in music therapy is to build trust and improve familiarity with the participant. This is the most important part of my findings. The relationship between the music therapist and the participant is based on a sense of trust and familiarity. Participants do not open their heart and express their real feeling and thoughts to an unfamiliar and distrustful person.

After numbers of reviewing data, rethinking my themes combined with my experience and reflections, I think building trust and familiarity in music therapy creates a safe environment for participants, which includes understanding and respecting the child's current moods, behaviours; and following the child's lead.

Respecting a child as an equal musical partner involves following their lead, talking about things, singing songs as well as playing games that go along with their interests are able to enhance their engagement, participant, and building up the connection within a social context (Lowry, 2016; Grosz et al., 2010; Hoskyns, 2009).

\subsubsection{Understanding and Respecting the child's doing}

- Keeping a safe distance

- Keeping the same height as the child

- Allowing space for the child

- Observing what the child's doing

In my coding analysis process, I divided "Understanding and Respecting the child's doing" into four factors: 1) Keeping a safe distance; 2) Keeping the same height as the child; 3 ) Allowing space for the child; y4) Observing what the child's doing. 


\section{$\underline{\text { Keeping a safe distance }}$}

From a large number of music therapy videos and case study literature examples, many young age participants presented nervous and afraid in their first music therapy session. Although some of them were with parents or teacher's accompanying them as, they might still feel unsafe facing strangers or new place. They might be afraid, cried, or try to escape from the music therapy room.

When the child is in a bad mood or frustrated about the current situation, the music therapist should provide enough personal space for the child, and keep a safe distance from the child. The distance between the music therapist and the child can vary depending on the level of trust and familiarity. According to the personal space distance reference in the United States, different levels of relationships determine the comfort distance between two people. The appropriate distance for people who do not know each other well is more than four feet. This distance creates a comfortable zone for both people to start a conversation.

\section{Keeping the same height as the child}

The sentence "keep the same height" appeared in my coding several times. According to my observation of the music therapy videos between the adult music therapist and child participant, I found that almost all music therapists keep the same height as their child participants. Most of the cases are both the music therapist and participant sitting on the floor or sitting on chairs and according to the survey, maintaining the same height as the child indicates that you are willing to respect the child as an equal partner. Alderson (2008) described that music therapists should respect children's rights, thinking and behaviours working with young children (Alderson, 2008).

\section{Allowing space for the child}

When the child participant is crying or yelling, it is a way for the child to express their emotions and feelings. They might not know how to say it in words, or they might not be willing to share it with language. The behaviour may release their emotions help them to reduce stress, and to relax. At the same time, allowing space for the child conveys the respect attitude from the music therapist. Nolan, in her study in 2005, suggests that providing enough time 
for silence is critical for both music therapists and participants to have a break and relax while thinking about music activities (Nolan, 2005). For example, when the child participant cries during the music therapy session, the music therapist stays quietly with the child. It conveys a message to the child participant that "it is okay for you to cry. Here is safe and I will be with you".

Example from literature:

'The use of a variety of improvisation techniques and musical variation served to maintain the interest and attention in the interaction, and aid in the buildup of musical tension and excitement. It was often important for the therapist to wait for the child to initiate and respond' (Perry, 2003, p. 237).

\section{Observing what the child is doing}

Music therapists try to understand the child's current feeling and thinking through observing what the child is doing at the moment_— this includes the child's facial expression, body movement, speaking tones. For example, if the child is curious or interested in something, he may stare at it for a long time, trying to touch it, or point it out with fingers. In contrast, if the child does not like something, he might show a strong refusal attitude or behaviours such as shaking the head, crying, becoming angry and ignoring. It is essential for music therapists to keep observing the child's behaviours and be aware of the changes immediately.

An example of Understanding and Respecting the child's doing:

There are two music therapists, Benji, and Benji's mother in the music therapy room. From the video, Benji seemed stress with the music therapy environment. He hid in his mother's arms and turned his back on the music therapists with crying and yelling. He wept more when the therapists tried to approach him.

From the video, the two music therapists sat about one meter away from the child, smiling and looking at the child quietly. They didn't play and music until the child stopped crying. (Description of video "Benji-A journey to speech"). 


\subsubsection{Following the child's lead (Clinical improvisation method)}

- Singing about the current situation

- Matching the current atmosphere

- Matching the child's current mood

- Mirroring the child's behaviours

- Changing with the child

According to my analysis, I divided "Following the child's lead" into five critical parts: 1)Singing about the current situation; 2)Matching the current atmosphere; 3) Matching the child's mood; 4) Mirroring the child's behaviours; 5) Changing with the child.

\section{Singing about the current situation}

A Music therapist connects to the current situation and singing together through singing everything that happened in the moment. Such as the weather outside the window; the instrument the music therapist played; the sound that made by the child; the body movement that the child's doing. It promotes awareness about reality. Bruscia (1987) believes that using clinical improvisation method in music therapy can help participants to express their feelings and learn communication skills while enhancing the sense of self-understanding (Bruscia, 1987).

\section{Matching the current atmosphere}

Matching the current environment and the child participant's dynamic is a crucial part in improvisation method. For example, if the music therapy room is quiet, and the participant seemed anxious and uneasiness at that moment. If the music therapist plays in a loud and energetic way it might cause the child discomfort and increase anxiety.

\section{Matching the child's current mood}

It is important that the music therapist responds to the needs of participants for music therapist by adapting the music flexibly with the participants at the moment, especially when the participant is in a frustrated or angry mood.

Wigram in 2004 described that the music therapist responds to the clients' body posture, facial expression, attitude, personality and characteristics as empathic improvisation (p89). This type of 
improvisation method not only focuses $\mathrm{n}$ the music-making between the music therapist and participants but also aims o facilitate the participant's mood within a session (Wigram, 2004). Bruscia described a similar opinion as music therapist should be reflecting from 'matching the moods, or feelings exhibited by the client' (Bruscia, 1987, p.540).

\section{Mirroring the child's behaviours}

Wigram (2004) defined mirroring as, 'doing exactly what the client is doing musically, expressively and through body language at the same time as the client is doing it. The client will then see his or her own behaviour in the therapist's behaviour' (p. 82).

Music therapists copy the child's behaviours, facial expression, sounds, and present back to the child in a musical and expressive way. It provides an opportunity for the child to develop a sense of experiences, reality and self-awareness ability.

\section{Changing with the child}

Many pieces of literature emphasize that music therapists should have abilities to be flexible in the moment; using multiple strategies and techniques to match children's arising needs such as matching, modelling, musical dialoguing, turn-taking, mirroring, fill in the gap as well as creating musical pause (Leung,2008; Oldfield, 2006). Oldfield in 2006 emphasized singing, playing, talking, and musicmaking was important when working with children.

Examples to "Following the child's lead":

1. When Benji calmed down and stopped crying, the room was quiet. The female music therapist played a few broken chords with the guitar softly and slowly. It caught Benji's attention quickly. Benji turned his head back and looked at the female therapist a few times. At this time, the female music therapist smiled kindly and sang gently "Hello, Benji. Hello, Mom”.

When Benji looked relaxed, the male music therapist joined in. He sat close to Benji and handed a drum sticker to Benji with singing "Hello, Stick". Then the male music therapist picked up the wooden frog castanet. He played it with singing "Hello, Frog. Hello, Benji". The male music therapist timed with Benji's arms shaking movement. Benji showed his interest and curiousity in the wooden frog castanet. He turned his body around and kept looking at it. (Description of video "Benji-A journey to speech"). 
2. The music therapist was looking at the child participant, using the loud singing and loud playing, timing with the participant's lift up and down movements. At first, I was thinking the music therapist was modelling and leading the lift up and down movements, and then I found that she was copying with the girl's movements. (Reflection of video "Mary and Antonia").

3. From 0:27, They changed their playing pattern. The girl stopped playing on the keyboard. She took control in the left side ideo. The music therapist played what the participant offered. When the participant lifts the arms up, the music therapist sang and lifted arms up; when she lift arms down, the music therapist played on the keyboard; when she waved her right arm, the music therapist scratched her right hand on the keyboard. And the music therapist responded to this by played staccato and short chords when the girl waved her arm up and down quickly. The way of playing on the keyboard, including the volume, speed, timbre depending on the participant's actions (Description of video "Mary and Antonia").

4. The music therapist was playing his guitar, and the boy is singing. He sang a long "Ai " in about $F$ note, and then changed to $E$ and $G$ with a crescendo. The music therapist played the guitar, changed the chords, and changed the strength from softer to louder matched the boys singing. The boy gave an eye-contact to the music therapist before he changed the pitch to $G$, and the music therapist changed the chord at the same time (Description of video "Music therapy shows how musical improvisation benefits children with special needs).

\subsection{Moving up Together}

\section{$\checkmark$ Creating Enjoyment}

\section{$\checkmark$ Musical Collaboration}

"Moving up together" is the third theme which builds on the second theme music therapist establishes a strong trust relationship with the participant, a core aim is to encourage elop through explore, enjoy and cooperate with the music therapist in a musical environment.

\subsubsection{Creating Enjoyment}

- Child-like Instrument

- Child-like songs

- Child-like games 
- Simple content

Some literature suggests that the playfulness within the session strengthens the therapeutic relationship, and improves the musical understanding and reciprocity. Choosing appropriate and tailored songs and videos based on each child's individual needs and interest are essential. (Aldridge, 1996; Grosz et al., 2010; Hoskyns, 2009; Michel \& Jones, 1991). Encouraging children to recreate children's familiar songs such as "Row Row Row your Boat", "If you are happy", "Five Little Monkeys" are able to improve children's engagement and anticipation, and motivate contribution content in the music, and evoke the sense of achievement and ownership (Beathard \& Krout, 2008; DeThorne et al., 2009; Michel \& Jones, 1991).

Young children are easier to engage and pay more attention to others when someone talks about his/her interested things, plays his/her favourite songs (Lowry, 2016). Many music therapists found that involving singing familiar nursery songs, Peek-a-boo and finger games, animal and vehicle sound imitation within the music therapy activities can help children to reduce anxiety, and building the concepts of communication including sharing, relatedness, collaboration skills (Beathard \& Krout, 2008; Hoskyns, 2009; Oldfield, 2000, 2006).

For example:

1. When Benji jumped from the drum, the music therapist played two chords with staccato. And she played in a fast and energetic way on the piano. Benji seemed very exciting. He drummed several times on the drum by his hand and stomped on the ground drum by his foot. The music therapist kept changing and adapting the playing way to match Benji's emotion and movement change. She played glissando, staccato, and sang very simple words "la la la".

Benji seemed happy and enjoyed the musical activity with the music therapist. He laughed when he jumped on the floor, and the music therapist played the glissando at that time. The music therapist timed Benji's stomp pattern on the drum. And it generates eye-contact between Benji and the music therapist during the playing(Description of video "Benji-A journey to speech").

2. In 3:36, the music therapist sang "twinkle twinkle little star", and shook the shakers with the child together. He stopped after singing and asked, "should we do more". The child was able to press the "yes" button on the screen directly. It seemed he understood that 
after he pressed the "yes" button, the music will go on (Description of video "Music Therapy for Autism: How to use simple instruments to help children").

\subsubsection{Musical collaboration}

- Modelling

- Fill-in the blank

- Turn-taking

- Verbal and Non-verbal interaction

Modelling

Wigram defines modelling in clinical improvisation as "playing and demonstrating something in a way that encourages the client to imitate, match or extend some musical ideas' (Wigram, 2004, p. 99). Children can understand more easily by seeing how the music therapist does it, and it engages the observation at the same time.

For example:

In 3:47, there is Benji, two music therapists in the room. The music therapists sang "If you are happy" song. The female music therapist created a space after singing "If you are happy and you know it shouts Hay!", she modelled with putting her hands up and open her mouth big. Benji copied her movement; he opened his mouth big. But he didn't make the "Hay" sound at this time. In 4.00, the music therapists sang "twinkle twinkle little star", she created a space in "like a diamond in the ....", "twinkle twinkle little ......" and encourage Benji to fill in the blank. She used a very familiar song, sang it very slowly with repetition(Description of video "Benji-A journey to speech").

\section{$\underline{\text { Fill- in the blank }}$}

McMahan considered that Children are inspired to associate reality with ideals by experiencing the free exploration and creation of the play and the release of imagination in the process of repeated experiments (McMahon, 2009)

For example: 
In 4:07, the music therapist sang "so we ask for a " and created a long blank. He stopped singing, and guitar playing, and then looked at the boy and waiting for his response. After about 40 seconds waiting, the boy looked back to the music therapist and said "a.... a.....", "I feel sunny". And the music therapist repeated the phrase again "We ask for a .....", and the boy filled in "Grade" (Description of video "Music therapy shows how musical improvisation benefits children with special needs).

\section{Turn-taking}

Wigram (2004) described turn-taking as 'Making music together where the therapist or client(s) in a variety of ways, musical or gestural, can cue each other to take turns.' (p. 98). And he further suggests that creating pauses between the musical play of music therapist and participant is necessary. Turntaking within musical conversation brings an experience for children to wait for a turn, and tolerate the waiting with a patient, in a playful and relaxed way 019). Turn-taking within musical improvisation is evoking responses from both young children and music therapists. And it also helps to improve joint attention, listening to others that are able to affect children's communication development( Bunt, 1994; Wigram et al., 2002).

For example:

The boy stopped singing for a few seconds; he looked at the music therapist. The music therapist kept playing on the guitar; the music was continued playing. The boy made a few sounds, and he seemed a bit embarrassing. The music therapist started to singing "we feel the beat" at this moment. The boy started to rock his body again, following the music therapist singing. He sang again after the music therapist slowed down and stopped singing (Description of video "Music therapy shows how musical improvisation benefits children with special needs).

\section{$\underline{\text { Verbal and Non-verbal interaction }}$}

Some music therapists considered that clinical improvisation should include verbal interaction. They suggest that playing music in the therapeutic process is important. However, generating verbal interaction, and speaking to participants are also critical in facilitating speech and language 
development (Nicholls, 2002; Nolan, 2005; Pavlicevic, 2000). This idea was also be stressed in Simpson's study in 2000. He considered that verbal interaction plays a necessary and critical role in creative music therapy. He described that the 'verbal relationship must play a part, simply because it exists: it would be unnatural not to speak, it must be allowed to integrate naturally into the therapy' (p. 90) (Simpson, 2000). Loewy recommended that using vocal holding technique, grounding and mirroring in music therapy are helpful to support and evoke participant's vocal response (Lowey, 2004).

For example:

1. After a few times repeating the songs, he stopped and asked: "should we do some more....?" He created a pause, and looked to the platform, waited for the child's response. The child pressed the "Yes" button. And the music therapist started singing with another song "Let's play those shakers today. Let's all play today.". After this song, he sang "I say ......" and waited to the child's response. The child pressed the "yes" button again. And the music therapist sang "Yes" song again. The child held shakers with the music therapist together through the music therapist's singing (Description of video "Music Therapy for Autism: How to use simple instruments to help children”).

2. The music therapist was singing a long "Ey", "Whoo", "Ah" loudly and lifting the arms, and then stopped singing or singing very lightly when lifting down the arms and playing on the keyboard with strong chords matched the participant's movements( Description of video "Mary and Antonia"). 


\section{Discussion}

\subsection{What I found essential from this research relating to my practice experience}

From my finding of this research, a child-centred music therapy model is the most important part of using clinical improvisation to support preschool children's speech and expressive language development. Creating a child-attractive, safe and relaxed music environment can motivate children's communication intent with confidence. Music therapy is able to provide individualized music making, creating meaningful and expressive songs that can address the child's needs of speech production and language understanding and expression through the music therapy process. Through motivating, modelling with repetition, planning individualized structured musical activities, music therapy can provide contribution in various speech and language developmental areas.

Furthermore, through this research process, I found that in music therapy, music therapists can encourage children's cooperative and collaborative intentions by creating and exploring music in relaxed, interesting and enjoyable ways to achieve the specific goals of speech and expressive language development. Music therapists can use rich facial expressions to prolong pronunciation, emphasize and stress accents, to make the music-making process more playful, attractive, meaningful and targeted. For example, I can imitate the animal sounds with various expression way in "Old McDonald had a farm". I can make "mou" sound with thick low pitch sound to present cow's big and heavy imagine; and sing "ji" sound with short and light high pitch sound to present bird's small and cute imagine, to evoke child's imagining sense and enhanced the child's engagement.

Many music therapy articles discuss that when working with preschool children, techniques including play, creativity, and collaboration, were essential (Beathard \& Krout, 2008; Hoskyns, 2009; Wilkinson, 2008). Many music therapists found that involving singing familiar nursery songs, Peek-a-boo and finger games, animal and vehicle sound imitation within the music therapy activities can help children to reduce anxiety, and building the concepts of communication including sharing, relatedness, collaboration skills (Beathard \& Krout, 2008; Hoskyns, 2009; Oldfield, 2000, 2006). 
On the other hand, some music therapist emphasized that play is the core concept of musical interaction, creating a playful musical atmosphere, including playful musical activities and songs are helpful and critical when working with the goal of facilitating the development of speech and language with young children(Bunt, 1994; Bunt \& Stige, 2014; Perry, 2003). Some music therapists in their studies confirmed that young children need to develop their sense of experiences, reality, self-awareness, and to improve the sense of self-exploration, creativity and imaginativeness in children's development. They suggested that providing enough space for children to play and explore freely is helpful to reach those goals (McMahon, 2009; Stern, 1977; Winnicott, 1971). Beathard \&Krout (2008) and Hoskyns(2009) said that children with speech and expressive language difficulties are more engaged with doing free and playful vocal exploration (Beathard \& Krout, 2008; Hoskyns, 2009). It is helpful for young children to improve narration ability through providing children chances to express their emotions in music therapy, such as doing free vocal creation and exploration like vowel sounds "ah", "oo", "ee” etc. (Bunt, 2014; Oldfield, 2006). Beathard and Krout considered that encouraging children to initiate any vocal sounds such as mimicking animal, vehicle sounds while participant to musical activities, instrument or toy exploring (Beathard \& Krout, 2008).

'The pleasure and excitement of playing, the intensity and concentration, the freedom to experiment, to explore and to create, to find out how things and people work and what you can do with them, to give the imagination free rein, and to fill the gap between reality and desire, all these derive from the fact that in play the child is in charge.' (McMahon, 2009, p.6)

\subsection{Learning from this research}

Throughout a few months research process, it brought me a lot of self-development in various areas including the professional knowledge; confidence; and opening my mind.

\section{- Building up my professional knowledge and confidence}

During the span of this research process, my knowledge has been growing with the increased amount of and in my descriptions of videos, and the clinical notes in my placement experiences. I used more professional terms such as receptive language, communication content, joint attention. The observation of video, as well as my daily practice, were becoming more detailed. I noticed that as the understanding of music therapy developed, the 
confidence of describing and explaining to staff what music therapy can do to benefit others also grew.

\section{- Open my mind broadly}

As a music therapy student and a classical piano player, doing this research has influenced my way of thinking. I start to think deeper when I am performing on the piano as well as music therapy practical works. For example, I increase the eye-contact with the audiences, and I start to observe their facial expressions and body response more as a pianist. At the same time, I consider the use of playing techniques more carefully; the way of adapting my playing is more flexible. For example, I aware that I should play more energetically if my participant is jumping; and slow down if the participant shows confused expression.

\subsection{Limitations of this research}

COVID-19 brought a lot of change to our lives this year. After 14 days of self-isolation in Thailand in February, I came back to New Zealand in March safely in March. However, more than one-month lockdown happened at the end of March. All people had to stay at home for safety. The start of my practicum has been delayed. Therefore I decided to focus my research on what can be learned from literature, interaction with team members, and online resources as theoretical research.

Doing theoretical research provided me with a chance to read a number of related readings, which helped me establish a fundamental professional understanding. It provided me with a lot of thinking and understanding while watching online resources. However, As a secondyear student, I do not have rich music therapy experiences and understanding; there may be still a lot of space for analysis and development in my findings.

As the difference of doing secondary analysis, there were no active research participants in this theoretical exploratory research, which means data what I used are not my own working experience. The disadvantages of analyzing resources from other music therapist are that I could only describe what I observed from the video, and thinking about the techniques the music therapist used in the video. The uncertainty of this research is, what I saw and 
described from the audiovisual recording only represents my personal understanding instead of the real thought of the music therapist of the video. 


\section{Conclusion}

The purpose of this exploratory research was to explore how music therapy supports speech and language development for young children with complex needs in specialist conductive education service. This research focused on finding out through literature, online video and documented experiences of the research what other music therapists do to help children with speech and language difficulties and what kind of interventions, resources and practical support music therapists provide; what meaning they give to their actions; and what issues are considered for various levels of support.

The thematic analysis identified three central themes in how music therapists support speech and language development. These were: "Flexible Musical Techniques" which includes timing, tempo adaption, and dynamic adaption; "Building trust and familiarity" between therapist and child; and the secondary theme or process of what I described as "Moving up together" which involved musical collaboration and mutual enjoyment. Throughout these processes therapists used an underpinning strategy at all levels, which I described as "flexible musical skills" (which included adaptations to timing with the child, and to tempo and dynamics).

Therefore, this could be described as an emerging theoretical framework (Stebbins, 2001) to guide a music therapist or student such as myself in approaching the support of young children's speech and language development. While I am limited in experience as a practitioner, learning from a range of literature sources, and practical videos and building reflections alongside practice (which developed later in my placement) was a valuable process to develop confidence and practice wisdom. 


\section{APPENDIX 1: AN EXAMPLE OF CODING FROM THE VIDEO DISCRIPTIONS}

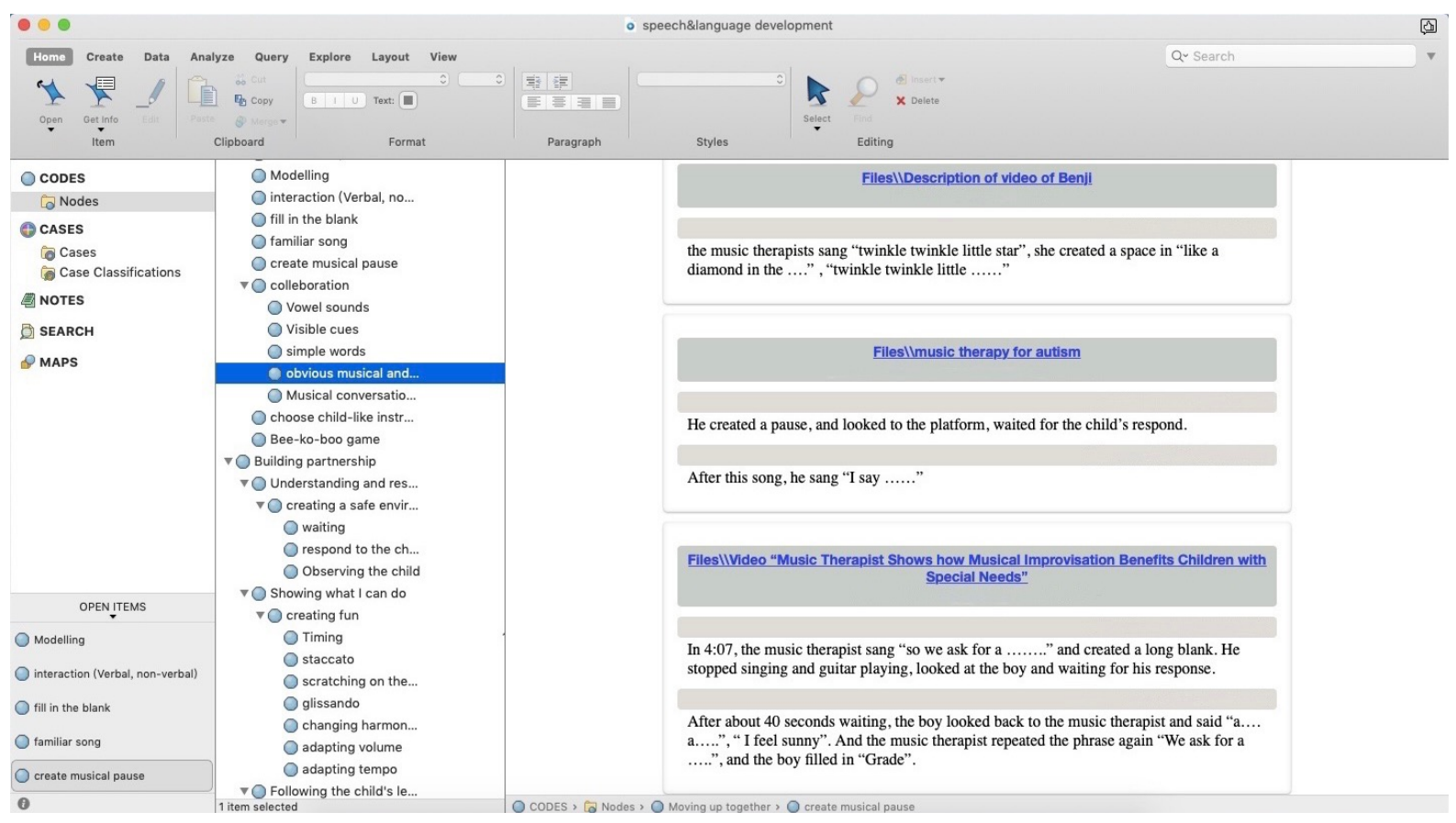

\section{APPENDIX 2: AN EXAMPLE OF CODING FROM THE LITERATURE (PERRY (2003)).}

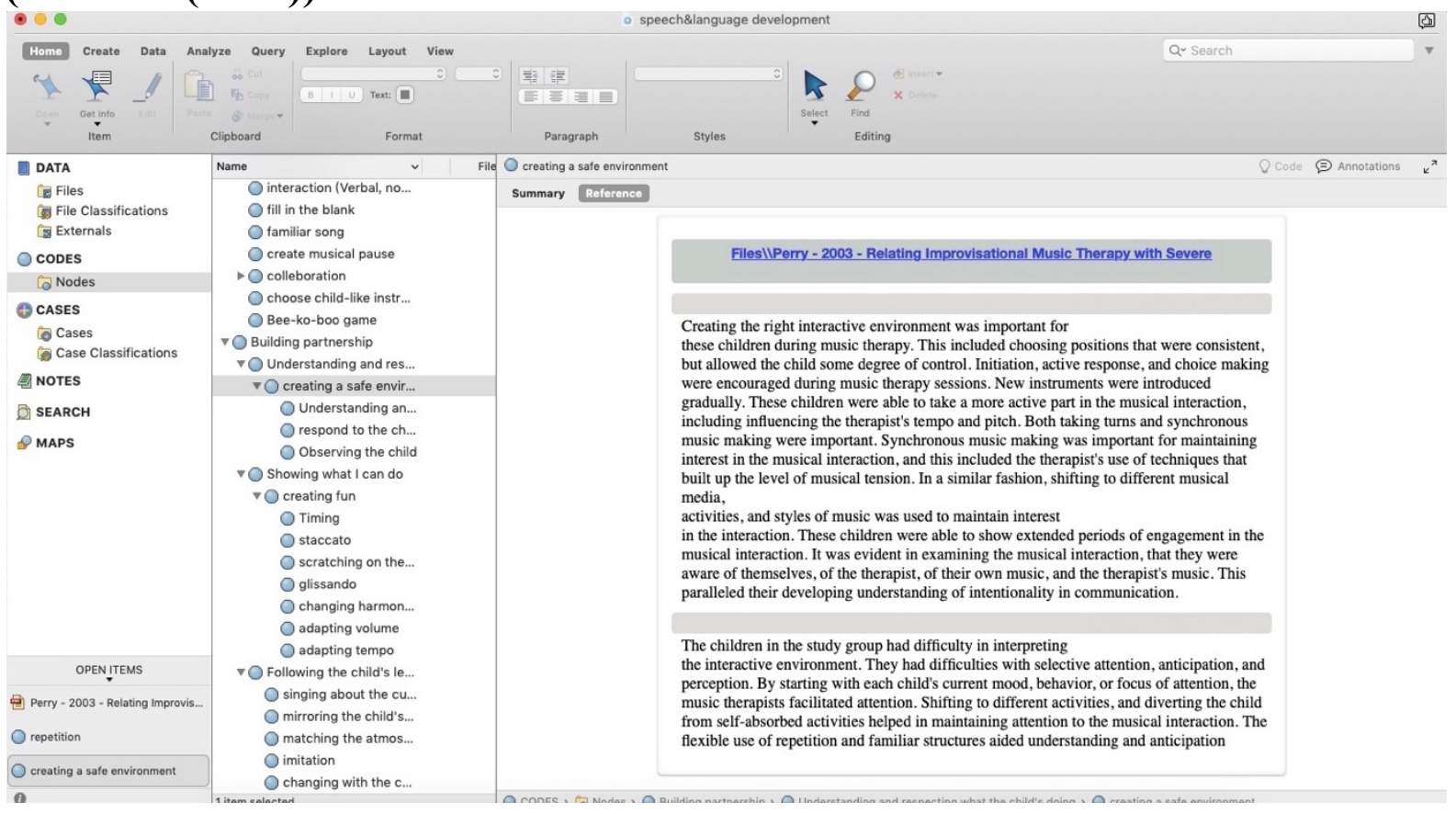




\section{References}

Alderson, P. (2008). Young children's rights : exploring beliefs, principles and practice (2nd ed.). Jessica Kingsley Publishers.

Aldridge, D. (1996) Music Therapy Research and Practice in Medicine: From Out of the Silence. London: Jessica Kingsley.

American Psychiatric Association. (2013). Diagnostic and statistical manual of mental disorders (5 $5^{\text {th }}$ ed.). Arlington. VA: Author

Beathard, B., \& Krout, R. E. (2008). A music therapy clinical case study of a girl with childhood apraxia of speech: Finding Lily's voice. Arts in Psychotherapy, 35(2), 107-116. doi:

10.1016/j.aip.2008.01.004

Braithwaite, M., \& Sigafoos, J. (1998). Effects of Social versus Musical Antecedents on Communication Responsiveness in Five Children with Developmental Disabilities. Journal of Music Therapy, 35(2), 88-104. https://doi.org/10.1093/jmt/35.2.88

Braun, V., \& Clarke, V. (2006). Using thematic analysis in psychology. Qualitative Research in Psychology, 3(2), 77-101. https://doi.org/10.1191/1478088706qp063oa

Bruce, A., \& High, S. (2012). Multiple views of music therapy. In J. Tomlinson, P. Derrington, \& A. Oldfield (Eds.), Music therapy in schools. Working with children of all ages in mainstream and special education (pp. 71-83). London, Philadelphia: Jessica Kingsley Publishers.

Bruscia, K.E. (1987). Improvisational models of music therapy. Springfield, Illinois: Charles

Bruscia, K.E. (2005). Developing Theory. In B.L.Wheeler (Ed.), Music Therapy Research (2 ${ }^{\text {nd }}$ ed., pp.540-551). Gilsum, N.H.: Barcelona Publisher

Bunning, K. (2003). Speech and language therapy intervention : frameworks and processes. London: Whurr

Bunt, L. \& Stige, B. (2014). Music therapy: An art beyond words (2nd Ed.). New York, NY: Routledge. 
Carpente, J. A. (2017). Investigating the effectiveness of a developmental, individual difference, relationship-based (DIR) improvisational music therapy program on social communication for children with autism spectrum disorder, Music Therapy Perspectives, 35(2), 160-174.

https://doi.org/10.1093/mtp/miw013

Carroll, D., \& Lefebvre, C. (2013). Clinical Improvisation Techniques in Music Therapy: A Guide for Students, Clinicians and Educators. Springfield: Charles C Thomas Publisher.

Cohen, N. S. (1992). The effect of singing instruction on the speech production of neurologically impaired persons. Journal of Music Therapy, 2, 87-102.

Darnley-Smith, R. \& Patey, H. M. (2003). Creative Therapies in Practice: Music therapy London: SAGE Publications Ltd.

Davis, W., Gfeller, K., \& Thaut, M. (2008). An introduction to music therapy : theory and practice (3rd ed.). American Music Therapy Association.

DeThorne, L. S., Johnson, C. J., Walder, L., \& Mahurin-Smith, J. (2009). When "Simon says" doesn't work: Alternatives to imitation for facilitating early speech development. American Journal of Speech-Language Pathology, 18(2), 133-145. doi: 10.1044/1058-0360(2008/07-0090)

Feldberg. (2000). 'Bingo Lingo: Supporting Language Development through Songs and Rhymes'. British Journal of Music Education 17(3):303-16

Gross, W., Linden, U., \& Ostermann, T. (2010). Effects of music therapy in the treatment of children with delayed speech development - results of a pilot study. BMC Complementary and Alternative Medicine, 10, 39, http://dx.doi.org/10.1186/1472-6882-10-39.

Grosz, W., Linden, U., \& Ostermann, T. (2010). Effects of music therapy in the treatment of children with delayed speech development - results of a pilot study. BMC Complementary and Alternative Medicine, 39. doi: 10.1186/1472- 6882-10-39

Guerrero, N., \& Turry, A. (2012). Nordoff-Robbins music therapy. An expressive and dynamic approach for young children on the autism spectrum. In P. Kern \& M. Humpal (Eds.), Early childhood music therapy and autism spectrum disorders. Developing potential in young children and their families (pp. 130-144). London, Philadelphia: Jessica Kingsley Publishers

Hoskyns, S. (2009, July). Promoting readiness for learning in a pre-school child with features of developmental dyspraxia: Some strategies from music therapy. In G. Wallis \& D. Sell (Eds.), Music 
'09 Modulations: Proceedings of the New Zealand National Music Education Conference (pp.22-39). Christchurch, New Zealand: Music Education Canterbury in association with Music Education New Zealand Aotearoa.

Joshi, P., \& Shukla, S. (2019). Learning in Early Childhood. In Child Development and Education in the Twenty-First Century(pp. 63-81). Springer, Singapore.

Kenny, C. (2006). Music and life in the field of play. Gilsum, NH: Barcelona Publishers.

Kern, P. (2006). Using embedded music therapy interventions to support outdoor play of young children with autism in an inclusive community-based child care program. Journal of Music Therapy, 43, 270-294, https://doi.org/10.1093/jmt/43.4.270.

Knight \& Rabon (2017). Music for speech and language development in early childhood populations. Music Therapy Perspectives, 35(2), 124-130

LaGasse, A. B.(2017). Social outcomes in children with autism spectrum disorder: A review of music therapy outcome. Patient-Related Outcome Measures, 2017(8), 23-32.

Leung, M. (2008). A collaboration between music therapy and speech pathology in a paediatric rehabilitation setting. Voices: A World Forum For Music Therapy, 8(3).

Lim, H. (2010). Effect of "developmental speech and language training through music" on speech production in children with autism spectrum disorders. Journal of Music Therapy, 47, 2-26, https://doi.org/10.1093/jmt/47.1.2.

Loewy, J. (1995). The musical stages of speech: A developmental model of pre-verbal spind making. Journal of Music Therapy, 12, 13-20

Loewy, J. (2004). Integrating Music, Language and the Voice in Music Therapy. Voices: a World Forum for Music Therapy, 4(1), NP. https://doi.org/10.15845/voices.v4i1.140

Lowry, L. (2016). "Tuning in" to others: How young children develop theory of mind. The Hanen Centre. Retrieved November 26, 2019, from http://www.hanen.org/Helpful- Info/Articles/Tuning-Into-Others-How-Young-Children-Develop.aspx

Lorenzato, K. (2005). Filling a need while making some noise : a music therapist's guide to pediatrics (1st American pbk. ed.). Jessica Kingsley Publishers. 
Malloch, S., \& Trevarthen, C. (Eds.). (2009). Communicative musicality: Exploring the basis of human companionship. Oxford, England: Oxford University Press.

McMahon, L. (2009). The handbook of play therapy and therapeutic play (2nd ed.). Hove, England: Routledge.

McCarthy, J., Geist, K., Zojwala, R., \& Schock, M. Z. (2008). A survey of music therapists' work with speech-language pathologists and experiences with augmentative and alternative communication. Journal of Music Therapy, 45(4), 405-426.

Michel, D. E., \& Jones, J. L. (1991). Music for Developing Speech and Language Skills in Children: A Guide for Parents and Therapists (Vol. 9). Saint Louis: MMB Horizon Series.

Miendlarzewska, E. A., \& Trost, W. J. (2014). How musical training affects cognitive development: rhythm, reward and other modulating variables. Frontiers in neuroscience, 7, 279.

Music Therapy New Zealand. (2012) Code of Ethics for the Practice of Music Therapy in New Zealand. Retrieved from https://www.musictherapy.org.nz/wp-content/uploads/2018/11/MThNZCode-of-Ethics-2012-LS-12.11.18.pdf

Newham, P. (1998). Therapeutic voicework : principles and practice for the use of singing as a therapy. London Philadelphia: Jessica Kingsley Publishers

Nicholls, T. (2002). “Could I play a different role?”-Group music therapy with severely learning disabled adolescents In A. Davies \& E. Richards (Eds.), Music therapy and group work- sound company. London: Jessica Kingsley Publishers.

Nolan, P. (2005). Verbal processing within the music therapy relationship. Music Therapy Perspectives, 23, 18-28.

Nordoff, P., \& Robbins, C. (1983). Music therapy in special education (2nd ed.). St. Louis, MO: Magnamusic-Baton.

Oldfield, A. (2000). Listening: The first step toward communicating through music. In P. M. a. B. Carolin (Ed.), Time to Listen to Children: Personal and Professional Communication (pp. 188-199). London and New York: Routledge.

Oldfield, A. (2006). Interactive music therapy - A positive approach: Music therapy at a child development centre. London, England: Jessica Kingsley Publishers. 
Ozdemir, S. (2009). Peer Relationship Problems of Children with AD/HD: Risk Factors and New Directions in Interventions. Australasian Journal of Special Education, The, 33(1), 42-59. https://doi.org/10.1375/ajse.33.1.42

Pavlicevic, M. (1997). Songs without words - Music in communication. In M. Pavlicevic (Ed.), Music therapy in Context - Music, meaning and relationship (pp. 98-117). London: Jessica Kingsley Publishers.

Pavlicevic, M.(2000). 'Improvisation on Music Therapy: Human Communication in Sound'. Journal of Music Therapy 37(4): 269-85.

Perry, M. M. R. (2003). Relating improvisational music therapy with severely and multiply disabled children to communication development. Journal of Music Therapy, 40, 227-246, https://doi.org/10.1093/jmt/40.3.227.

Rickson, D. (2019). Working in music with adolescents who experience disability. In Handbook of Music, Adolescents, and Wellbeing. Oxford University Press. https://doi.org/10.1093/oso/9780198808992.003.0013

Sawyer, R. (1999). Improvised Conversations: Music, Collaboration, and Development. Psychology of Music, 27(2), 192-205.

Sena Moore, K., \& Hanson-Abromeit, D. (2015). Theory-guided Therapeutic Function of Music to facilitate emotion regulation development in preschool-aged children. Frontiers in Human Neuroscience, 9, 572. https://doi.org/10.3389/fnhum.2015.00572

Seybold, C. D. (1971). The Value and Use of Music Activities in the Treatment of Speech Delayed Children. Journal of Music Therapy, 8, 102-110.

Silverman, M. J. (2007). The effect of paired pitch, rhythm, and speech on working memory as measured by sequential digit recall. Journal of Music Therapy, 44(4), 415-427.

Simpson, F. (2000). Speaking with clients. British Journal of Music Therapy, 14(2), 83-92.

Stebbins, R.A. (2001). Exploratory Research in the Social Sciences. Exploratory Research om the Social Sciences. SAGE Publications, Inc. Thousand Oaks, CA: SAGE Publications, Inc.

Thaut, M. H., Hoemberg, V., \& von, W. K. (Eds.). (2016). Handbook of neurologic music therapy. ProQuest Ebook Central https://ebookcentral-proquest-com.helicon.vuw.ac.nz 
Tierney, A. L., \& Nelson III, C. A. (2009). Brain development and the role of experience in the early years. Zero to three, $30(2), 9$.

Tuomi, K., Ala-Ruona, E., \& Oldfield, A. (2017). Literature Review of Early Childhood Music Therapy Between 1990-2012. Voices, 17(2). https://doi.org/10.15845/voices.v17i2.888

Tyler, H., M. (2002). Working, playing and relating: Issues in group music therapy for children with special needs. In A. Davies \& E. Richards (Eds.), Music therapy and group work - Sounds Company (pp. 216-230). London: Jessica Kingsley Publishers.

Victoria University of Wellington. (2019). Human ethics guidelines. Retrieved from https://www.victoria.ac.nz/documents/policy/research-policy/appendix-a-human-ethicscommittee-guidelines.pdf

Wheeler, B. (2005). Clinical Training Guide for the Student Music Therapist. Gilsum, N.H.: Barcelona Pub.

Wigram, T. (2004). Improvisation: Methods and techniques for music therapy clinicians, educators, and students. Jessica Kingsley Publishers.

Wilkinson, C. J. (2008). Reflections and analysis to improve clinical practice: A student music therapist's journey with a preschool child with special needs. Master of Music Therapy, New Zealand School of Music, Wellington.

Winnicott, D. W. (1971). Playing and reality. London, England: Tavistock Publications.

XMind Ltd (2006). Xmind (3.0.4) [Mobile app]. App Store. https://apps.apple.com/us/app/xmindmind-map/id1286983622 